Journal of Mathematics Education, 6(2) November 2020

\title{
Pengaruh Alat Peraga Mobil-Mobilan Terhadap Minat Belajar Matematika Siswa SMPN I Bola
}

\author{
Agustina Luju, Wahyuningsih, Magdalena Dhema, Muhamad Epi Rusdin \\ Program Studi Pendidikan Matematika, IKIP Muhammadiyah Maumere \\ *inhallchuex@gmail.com
}

\begin{abstract}
ABSTRAK
Alat peraga dalam dunia pendidikan merupakan suatu media yang menjadi perantara untuk membantu dalam memperjelas konsep dalam pembelajaran matematika. Penelitian ini bertujuan untuk mengetahui pengaruh penggunaan alat peraga mobil-mobilan terhadap minat belajar siswa pada mata pelajaran matematika khususnya materi perbandingan. Penelitian ini di lakukan di SMPN I Bola kelas VII semester 2 tahun ajaran 2019/2020. Jenis penelitian ini adalah kuantitatif dengan menggunakan metode quasi eksperimen. Populasi dari penelitian ini yaitu siswa kelas VII SMPN I Bola sebanyak 192 siswa dengan sampel sebanyak 23 siswa kelas eksperimen dan 23 siswa kelas kontrol. Teknik pengambilan sampel yang digunakan adalah dengan teknik acak kelas.Instrumen yang dipakaidalam penelitian ini adalah angket minat belajar. Sebelum melakukan uji hipotesis perlu di lakukan uji prasyarat yaitu uji normalitas dan homogenitas. Untuk uji normalitas diperoleh nilai signifikan pada kelas eksperimen dan kelas kontrol adalah 0,136 dan 0,620, karena nilai yang diperoleh taraf signifikannya $>0,05$ maka dapat dinyatakan data tersebut berdistribusi normal. Untuk uji homogenitas hasil yang diperoleh nilai signifikan adalah 0,001 pada taraf signifikan 0,05 sehingga dapat dikatakan data homogen. Setelah data berdistribusi normal dan homogen dilanjutkan dengan uji hipotesis. Pengujian hipotesis dengan menggunakan uji independent sample $\mathrm{t}$-test diperoleh nilai $\mathrm{t}_{\text {hitung }}>\mathrm{t}_{\text {tabel }}$ dimana $\mathrm{t}_{\text {hitung }}=6,49$ sedangkan $\mathrm{t}_{\text {tabel }}=2,01$ yang berarti bahwa penggunaan alat peraga mobil-mobilan berpengaruh terhadap minat belajar matematika siswa kelas VII SMPN I Bola dimana minat belajar matematika siswa meningkat. Dengan demikian guru dapat menggunakan alat peraga mobil-mobilan yang berhubungan dengan materi dan dapat digunakan dalam pembelajaran matematika sehingga minat belajar matematika siswa meningkat.
\end{abstract}

Kata Kunci: Alat Peraga Mobil-Mobilan, Minat Belajar, Pembelajaran Matematika

\begin{abstract}
Teaching aids in the world of education is a medium that mediates to help clarifying concepts in learning mathematics. This study aims to determine the efect of the use of toy car props on students' interest in learning mathematics, especially in comparison material. This research was conducted at SMPN I Bola VII class semester 2 of the 2019/2020 scholl year. This type of research is quantitative by using a quasi-experimental methods. The population of this study were 192 studentsof class VII SMPN I Bola with a sample 0f 23 students in the experimental class and 23 from the control class. The sampling technique used is class random technique. The instrument used in this study was a questionnaire of interest in learning. Before carrying out a hypothesis test it is necessary to do a prerequisite test that is a test for normality and homogeneit. The normality test obtained significant values in the experimental class and control were 0,136 and 0,620 , because the value obtained has a significance level of $>0,05$, it can be stated that the data is normally distributed. For the homogeneity test, the results obtained a significant value of 0,001 at a sisnificant level of 0,05 , so it can be said that the data is homogeneous. After the data is normally distributed and homogeneous, it is continued with hypothesis testing. Hypothesis testing used the independent sample t-test obtained value of $t$-count $>t$-table where $t$-count $=6,49$ while t-table $=2,01$ which means that the use of toy props has an effect on the interest in learning mathematics in class VII SMPN I Bola where students'interest in learning mathematics increases. Thus the teacher can use toy props related to the material and can be used in matematics learning so that students' interest in learning mathematics increases.
\end{abstract}

Keywords: Toy Props, Interest in Learning, Learning Mathematics

Received: 2020-07-12 ～～/ Accepted: 2020-09-24 / Publised: 2020-11-01

\section{Pendahuluan}

Permasalahan yang cukup rumit dalam dunia pendidikan ialah dimana peran seorang guru sangat berpengaruh dalam aktiitas pembelajaran. Kewajiban guru ialah memberikan sesuatu ilmu atau pengetahuan lewat hubungan komunikasi dalam proses pembelajaran yang sedang 
terjadi. Pada proses pembelajaran ketika guru belum menggunakan media yang menarik sangat berdampak terhadap siswa dimana minat siswa sangat minim dan siswa kurang aktif dalam pembelajaran (Nurkumalasari, 2016). Dari hasil pra survey dan wawancara kepada Guru matematika SMP N I Bola permasalahan yang sering terjadi di kelas diantaranya minat siswa rendah dan siswa kurang aktif dalam kegiatan pembelajaran karena pembelajaran bersifat monoton, kegiatan pembelajaran masih menggunakan metode konvensional, dimana peran seorang guru sangat dominan dalam aktifitas pembelajaran sehingga siswa kurang aktif dalam aktifitas pembelajaran. Selain itu aktivitas siswa kurang dilibatkan langsung dan kurang menciptakan apresiasi dan minat siswa sehingga hasil belajar siswa kurang maksimal.

Dalam dunia pendidikan, matematika tergolong dalam mata pelajaran yang bermanfaat pada aktifitas keseharian ataupun dalam kemajuan ilmu pengetahuan dan teknologi. Matematika merupakan ilmu yang penting karena banyak kegunaannya di setiap ilmu pengetahuan yang tidak lepas dari ilmu matematika (Alfiliansi, Ismaimuza, \& Rochaminah, 2014). Pada kenyataan matematika bukan hanya sebatas permasalahan hitung menghitung. Matematika adalah pelajaran utama (Manurung S. H., 2016). Banyak siswa menganggap matematika merupakan pelajaran yang sulit (Susanto \& Uswatun, 2017). Konsep matematika berupa bahasa simbolis yang abstrak sehingga siswa kesulitan dalam memahami pelajaran matematika (Ariyanti \& Husni, 2019). Belajar matematika merupakan aktifitas pokok, maka mengharuskan guru dalam meneliti memakai pendekatan atau metode dan berpengaruh dalam pembelajaran (Warsini, 2019). Suatu media sebagai alat bantu sangat di butuhkan dalam pembelajaran matematika pada materi yang bersifat abstrak (Nuryadi \& Bahtiar, 2017). Kepandaian siswa dalam menguasai pelajaran matematika dipacu melalui sistem pembelajaran yang dilengkapi melalui penggunaan alat bantu pengajaran. Alat bantu pengajaran mampu memajukan efektifitas mengajar yang bermanfaat dalam jenjang yang biasa atau sangat baik dan mampu merangsang minat siswa sehingga siswa mampu menguasai pelajaran matematika. Proses pembelajaran dilakukan melalui kegiatan mengajar disekolah yang diikuti oleh siswa dengan baik dan dilandasi dengan minat belajar yang tinggi sehingga siswa dapat menguasai pelajaran dengan sebaik mungkin karena minat banyak memberikan pengaruh pada sistem pembelajaran yang sedang terjadi. Jika pemanfaatan alat peraga diterapkan, maka diharapkan siswa mempunyai minat belajar yang tinggi pada mata pelajaran matematika.

Alat peraga merupakan suatu alat yang dipakai oleh seorang guru untuk menjelaskan suatu bahan atau wujud langsung matematika yang terencana sehingga bisa menunjang dan memahami dasar-dasar dalam matematika (Annisah, 2014). Pada pelajaran matematika ada materi dalam menjabarkannya membutuhkan alat bantu(Yensi, 2012). Alat peraga yang digunakan dalam penelitian ini adalah mobil-mobilan untuk pembelajaran pada materi perbandingan. Mobil-mobilan ini digunakan untuk memahami perbandingan senilai dan perbandingan berbalik nilai, dimana siswa dapat memperagakan sendiri dan dapat menarik kesimpulan sendiri setelah mendengar dan memperhatikan penjelasan dari guru tentang alat peraga mobil-mobilan.

Memacu minat belajar siswa pada pemelajaran matematika sangat penting (Sirait, 2016). Minat adalah rasa ketertarikan dan perasaan suka terhadap keadaan maupun situasi, tanpa ada orang yang meminta atau memerintahkan (Slameto, 2010). Minat adalah suatu ketertarikan yang meningkat dan mendalam yang disertai dengan perasaan suka terhadap suatu tindakan sehingga dapat menuntun anak untuk melaksanakan suatu kegiatan tersebut tanpa ada yang memaksa (Zusnani, 2013). Belajar adalah suatu perubahan pada pribadi seseorang sebagai pengalaman dalam berinteraksi dengana sesama (Manurung, 2016). Belajar adalah proses yang terjadi pada semua orang di kehidupannya (Arsyad, 2014). Proses ini disebabkan terdapat interaksi diantara individu dan lingkungan sekitarnya(Rahmawati \& Salwiana, 2016).Minat belajar adalah 
keinginan seseorang untuk memiliki perasaan bahagia tidak dengan paksaan hingga dapat merubah wawasan, keahlian dan sikap.

Penelitian ini relevan dengan penelitian yang dilakukan oleh Nurul Aisyanah dan Zunaida kurniasari. Dari hasil penelitian yang dilakukannya terbukti bahwa ada pengaruh minat dan hasil belajar siswa dalam pembelajaran matematika dengan menggunakan alat peraga(Aisyanah \& Kurniasari, 2017). Untuk meningkatkan minat belajar yang tinggi terhadap matematika maka pemanfaatan alat peraga harus diterapkan pada proses pembelajaran agar siswa memperoleh hasil belajar yang optimal. Dengan menggunakan alat peraga dapat memaksimalkan kemampuan siswa dan siswa semakin berperan dalam kegiatan pembelajaran.

\section{Metode Penelitian}

Penelitian ini merupakan jenis penelitian kuantitatif dengan pendekatan quasi eksperimen. Penelitian ini dilakukan di SMPN 1 Bola,Kabupaten Sikka, Provinsi Nusa Tenggara Timur pada tanggal 20 Januari-20 Februari 2020, dengan sampel sebanyak 23 siswa kelas ekperimen dan 23 siswa. Kelas kontrol. Dalam penelitian ini yaitu kelas eksperimen dengan perlakuan menggunakan alat peraga mobil-mobilan, dan kelas kontrol yang digunakan sebagai pembeda ialah kelas tanpa menggunakan alat peraga (pembelajaran secara konvensional). Metode pengumpulan data dengan menggunakan metode angket yang diberikan pada siswa setelah perlakuan pada kedua kelas. Sebelum melakukan penelitian ini diperlukan instrumen penelitian yang harus di validasi untuk memenuhi uji kelayakan. Validasi rancangan pelaksanaan pembelajaran (RPP) di validasi oleh dosen pendidikan matematika dan guru matematika SMPN I Bola, validasi alat peraga divalidasi oleh ahli media. Untuk validasi angket angket minat belajar matematika diperoleh dengan melakukan uji coba angket yang terdiri dari 35 pertanyaan angket minat belajar matematika. Uji coba angket dilakukan pada 32 siswa kelas VIII A SMPN I Bola. Berdasarkan hasil uji dengan menggunakan SPSS 22 terdapat 24 angket yang konsisten (valid). Perhitungan uji instrumen angket minat belajar matematis sebanyak 35 pertanyaan angket dengan responden sebanyak 32 peserta didik dimana $\alpha=0,05$ dan $r_{\text {tabel }}=0,349$ maka didapat 24 angket yang valid karena $r_{\text {hitu }}>r_{\text {tabel }}$. Uji reliabilitas bertujuan untuk mengetahui pertanyaan angket reliabil atau tidak (layak untuk digunakan atau tidak). Hasil perhitungan reliabilitas pertanyaan angket, dengan menggunakan SPSS 22 disimpulkan bahwa butir angket reliabel yang artinya pertanyaan angket dapat diuji cobakan. Dari ke 24 pertanyaan angket telah mencakup indikator minat belajar matematika

\begin{tabular}{llll}
\multicolumn{3}{c}{ Tabel 1. Kisi-Kisi Angket } & \multicolumn{3}{c}{ Minat Belajar Matematika } \\
\hline No & \multicolumn{1}{c}{ Indikator } & \multicolumn{2}{c}{ No. Item } \\
& & \multicolumn{1}{c}{$(+)$} & \multicolumn{1}{c}{$(-)$} \\
\hline 1 & Adanya perhatian & $2,6,13$, & $3,11,18$ \\
& & $22,23,10$ & \\
2 & Adanya ketertarikan & $1,9,16$, & $4,8,12$, \\
& & & 17 \\
3 & Adanya rasa senang & $5,7,14$, & 15,20 \\
& & $19,21,24$ & \\
\hline
\end{tabular}

Sebelum itu, dilakukan terlebih dahulu uji persyaratan analisis data, yaitu uji normalitas dan uji homogenitas dengan tahapan-tahapan sebagai berikut:

a. Pengujian persyaratan analisis yaitu uji normalitas menggunakan uji Kolmogorov-Smirnov dan uji homogenitas menggunakan One-Way,

b. Uji hipotesismenggunakan uji Independent Sample T Test. 
Agustina Luju, Wahyuningsih, Magdalena Dhema, Muhamad Epi Rusdin

Pengaruh Alat Peraga Mobil-Mobilan Terhadap Minat Belajar Matematika Siswa SMPN I Bola

\section{Hasil dan Pembahasan}

Penelitian ini ialah penelitian kuantitatif dengan 2 kelas yakni kelas eksperimen menggunakan alat peraga dan kelas kontrol tanpa menggunakan alat peraga (konvensional). Ada beberapa langkah-langkah yang dilakukan dalam penellitian ini yaitu perencanaan, pemberian perlakuan menggunakan alat peraga dan tanpa alat peraga, langkah terakhir pemberian angket minat belajar. Dalam penelitian ini diperlukan instrumen penelitian yang telah di validasi (memenuhi uji kelayakan). Instrumen di validasi oleh dosen pendidikan matematika, hasil uji validasi antara lain sebagai berikut: Validasi rancangan pelaksanaan pembelajaran (RPP), validasi alat peraga, dan validasi angket yang dikategorikan layak untuk digunakan.

Penggunaan alat peraga mobil-mobilan pada materi perbandingan senilai, bahan dan alat yang digunakan yaitu 1 buah mobil mainan, 1 buah tripleks sebagai tempat melintasnya mobil mainan dengan ukuran panjang $100 \mathrm{~cm}$ dibagi menjadi 4 bagian yang sama panjang, lebar 25 $\mathrm{cm}$, dan tebalnya $1 \mathrm{~cm}$, tinta digunakan untuk memerikan petunjuk berapa jumlah lintasan yang diperoleh mobil, isolasi kertas, gunting dan lem. Tahapan menggunakan alat peraga adalah: 1) Tempelkan isolasi kertas dibawah salah satu roda mobil mainan, kemudian beri tinta secukupnya pada isolasi kertas tersebut. Tujuanya agar dapat menghitung jejak putaran pada roda dengan panjang lintasan $25 \mathrm{~cm}, 50 \mathrm{~cm}, 75 \mathrm{~cm}$ dan $100 \mathrm{~cm}$. 2) Beri penopang kayu pada belakang salah satu ujung triplek agar mobil dapat meluncur. 3) Hitunglah banyaknya jejak putaran roda yang dihasilkan pada panjang lintasan yang berbeda yaitu $25 \mathrm{~cm}, 50 \mathrm{~cm}, 7 \mathrm{~cm}$ dan $100 \mathrm{~cm}$. Kesimpulannya yaitu semakin panjang papan lintasan maka semakin banyak putaran roda yang dihasilkan dan sebaliknya.

Pada perbandingan berbalik nilai bahan dan alat yang digunakan adalah 1 buah mobil mainan, 1 buah tripleks sebagai tempat melintasnya mobil mainan dengan ukuran panjang $100 \mathrm{~cm}$, lebar $25 \mathrm{~cm}$, dan tebalnya $1 \mathrm{~cm}$, kayu atau penumpu sebanyak 5 buah dengan ukuran panjang $25 \mathrm{~cm}$, lebar $4 \mathrm{~cm}$ dan tinggi $2 \mathrm{~cm}$, dan stopwatch untuk menghitung waktu tempuh. Tahapan menggunakan alat peraga adalah: 1) Beri 1 penopang kayu atau penumpu pada salah salah satu ujung belakang tripleks. 2) luncurkan mobil kemudian hitung kecepatannya dengan menggunakan stopwatch kemudian catat hasilnya. 3) Selanjutnya dengan menggunakan 2 penumpu-5 penumpu kemudian hitung kecepatannya dengan menggunakan stopwatch dan kemudian catat hasilnya. Kesimpulannya adalah semakin banyak penumpu yang digunakan maka semakin sedikit waktu tempuhnya dan sebaliknya.

Berikut ini adalah deskripsi beberapa analisis untuk menemukan sebuah hipotesis.

Uji Normalitas

Uji normalitas yang dilakukan adalah dengan menggunakan Test of Normality Shapiro-wilk. Hasil dari uji normalitas dapat dilihat pada tabel 2 berikut ini.

Tabel 2. Uji Normalitas

\begin{tabular}{lccc}
\hline Kelas & Post- & Keterangan \\
test & \\
\hline \multirow{3}{*}{ eksperimen } & Observer & 23 & \\
& hasil signifikansi & 0,136 & Berdistribusi \\
& taraf signifikansi & 0,05 & Normal \\
kontrol & Observer & 23 & \\
& hasil signifikansi & 0,620 & Berdistribusi \\
& taraf signifikansi & 0,05 & Normal \\
\hline
\end{tabular}

Berdasarkan data pada tabel 2 diatas diperoleh nilai signifikan pada kelas eksperimen dan kelas kontrol adalah 0,136 dan 0,620. Karena nilai yang diperoleh dari uji normalitas taraf signifikannya $>0,05$ maka data pada kelas eksperimen dan kontrol berdistribusi normal. 


\section{Uji Homogenitas}

Uji homogenitas menggunakan uji fisher. Hasil dari uji homogenitas dapat dilihat pada tabel 3 dibawah ini.

Tabel 3. Uji Homogenitas

\begin{tabular}{cccc}
\hline Levene statistic & df & Sig. & keterangan \\
\hline 12,171 & 44 & 0,001 & Data homogen \\
\hline
\end{tabular}

Berdasarkan hasil yang diperoleh pada tabel 3 di atas nilai signifikan adalah 0,001 pada taraf signifikan 0,05 sehingga dapat dikatakan data homogen.

\section{Pengujian Hipotesis}

Pengujian hipotesis dengan mnggunakan Uji independent sample t-test. Uji independent sample t-test di lakukan untuk mengetahui pengaruh perlakuan terhadap sampel yang berbeda pada klas eksprimen dan kontrol.Hasil dari Uji independent sample t-test dapat dilihat pada tabel 4 dibawah ini.

Tabel 4. Analisis Data

\begin{tabular}{ccc}
\hline & Eksperimen & Kontrol \\
\hline mean & 88,23 & 77,40 \\
observer & 23 & 23 \\
df & 42 & \\
$t_{\text {hitung }}$ & 6,49 & \\
Pvalue (sig.) & 0,000 & \\
$t_{\text {tabel }}$ & 2,01 & \\
\hline
\end{tabular}

Berdasarkan tabel 4 diatas diperoleh nilai $t_{\text {hitung }}>t_{\text {tabel }}$ dimana $t_{\text {hitung }}=6,49$ sedangkan $t_{\text {tabel }}$ $=2,01$ maka dikatakan bahwa ada pengaruh penggunan alat peraga terhadap minat belajar matematika siswa

Pada kelas eksperimen siswa belajar dengan menggunakan alat peraga mobil-mobilan yang bertujuan untuk meningkatkan minat belajar siswa. Pada akhir pembelajaran, peneliti memberikan angket berupa minat belajar siswa terhadap pelajaran matematika. Tampak terlihat bahwa banyak siswa yang berminat.

Proses pembelajaran yang dilakukan di kelas kontrol dimana pembelajarannnya konvensional. Ketika proses pembelajaran berlangsung, banyak siswa yang masih mengobrol dengan teman sebangkunya. Hal itu dikarenakan pembelajaran ini membosankan karena media yang digunakan kurang menarik.

Berdasarkan hasil analisis minat belajar menunjukan bahwa ada pengaruh penggunaan alat peraga mobil-moilan terhadap minat belajar siswa. Rata-rata minat belajar siswa kelas eksperimen lebih tinggi di bandingkan dengan kelas kontrol. Tingginya minat belajar siswa pada kelas ekspeimen di karenakan dalam kelas eksperimen pembelajaran dilakukan dengan menggunakan alat peraga mobil-mobilan sedangkan pada kelas kontrol minat belajar rendah di karenakan selama penelitian berlangsung pada kelas kontrol lebih banyak melibatkan peran aktif guru.

\section{Simpulan}


Agustina Luju, Wahyuningsih, Magdalena Dhema, Muhamad Epi Rusdin

Pengaruh Alat Peraga Mobil-Mobilan Terhadap Minat Belajar Matematika Siswa SMPN I Bola

Berdasarkan hasil analisis diperoleh nilai $t_{\text {hitung }}>t_{\text {tabel }}$ dimana $t_{\text {hitung }}=6,49$ sedangkan $t_{\text {tabel }}$ $=2,01$ dapat kita simpulkan bahwa terdapat pengaruh penggunaan alat peraga mobil-mobilan terhadap minat belajar matematika siswa pada kelas VII SMPN I Bola tahun ajaran 2019/2020. Dengan demikian dapat disarankan untuk guru sebaiknya dalam kegiatan pembelajaran dapat mengembangkan berbagai macam alat peraga benda-benda konkrit yang berhubungan dengan materi dan dapat digunakan dalam pembelajaran matematika sehingga minat belajar matematika siswa meningkat.

\section{Daftar Pustaka}

Aisyanah, N., \& Kurniasari, Z. (2017). Pengaruh model pembelajaran problem based learning dengan strategi alat peraga puzzle dadu terhadap minat belajar dan hasil belajar matematika. Jurnal Kajian Pendidikan Matematika , 3 (1), 33-44.

Alfiliansi, Ismaimuza, D., \& Rochaminah, S. (2014). Penerapan model pembelajaran kooperatif tipe stad berbantuan blok aljabar untuk meningkatkan hasil belajar siswa pada penjumlahan dan pengurangan bentuk aljabar di kelas viii smp negeri 12 palu. Jurnal Elektronik Pendidikan Matematika Tadulako , 2 (2), 127.

Annisah, S. (2014). Alat peraga pembelajaran matematika. Jurnal Tarbawiyah , 11 (1), 1-15.

Ariyanti, L., \& Husni, M. (2019). Pelatihan penggunaan alat peraga blok aljabar bagi guru matematika smp se-kabupaten banjar. Jurnal Pemberdayaan Masyarakat Berkarakter , 2 (2), 89-99.

Arsyad, A. (2014). Media pengajaran. Jakarta: PT Raja Grasindo Persada.

Manurung, S. H. (2016). Ipaya meningkatkan kreatifitas dan hasil belajar matematika siswa dengan megunakan model air (auditory, intellectually, repetition) pada siswa kelas viii MTs Negeri Rantauprapat t.p 2014/2015. Jurnal Edutech , 2 (1), 98.

Manurung, s. h. (2016). upaya meningkatkan kreatifitas dan hasil belajar matematika siswa dengan menggunakan madel air (auditory, intellectually, repetition) pada siswa kelas VIII mts Negeri rantauprapat t,p 2014/2015. jurnal edutech, 2 (1), 97-107.

Nurkumalasari, i. (2016). Skripsi peningkatan minat belajar matematika dengan mneggunakan media pembelajaran berbasis komputer (PTK Siswa Kelas VII Semester Genap MTs Negeri Ngemplak Boyolali). Yogyakarta: Universitas Muhammadiyah Surakarta.

Nuryadi, \& Bahtiar, Z. H. (2017). Pengembangan media pembelajaran matematika interaktif menggunakan adobe flash cs 5 pokok bahasan trigonometri untuk meningkatkan motivasi belajar siswa kelas X SMA. Alphamath (Journal of Mathematics Education) , 3 (1), 78.

Rahmawati, T. D., \& Salwiana. (2016). Pengaruh penggunaan alat peraga terhadap hasil belajar matematika peserta didik. BIRUNIMATIKA , 1 (2), 6 .

Sirait, E. D. (2016). Pengaruh minat belajar terhadap prestasi belajar matematika. Jurnal Formatif, 6 (1), 35-43.

Slameto. (2010). Belajar dan faktor-faktor yang mempengaruhi. Jakarta: PT Bumi Aksara.

Susanto, D., \& Uswatun. (2017). Hubungan antara kemandirian belajar, sikap siswa terhadap pembelajaran matematika dan kemampuan metakognisi dengan hasil belajar matematika siswa kelas x semester genap SMK Muhammadiyah Prambanan Kabupaten Sleman Tahun Ajaran 2015/2016. Journal of Mathematics Education (Alphamath) , 3 (1), 43.

Warsini, T. (2019). Penerapan model tai untuk meningkatkan kemampuan kerjasama dan hasil belajar matematika materi barisan dan deret kelas IXC SMP Negeri 4 Sumbang Semester 2 Tahun Pelajaran 2017/2018. Alphamath (Journal of Matematicks Education) , 5 (2), 914.

Yensi. (2012). Penerapan model pembelajaran kooperatif tipe examples non examples dengan menggunakan alat peraga untuk meningkatkan hasil belajar siswa di Kelas VIII SMP Negeri 1 Argomakmur. Jurnal Eacta, 1.

Zusnani, I. (2013). Pendidikan kepribadian siswa sd-smp. Jakarta: Platin. 